\title{
Variations in NAG-1 expression of human gastric carcinoma and normal gastric tissues
}

\author{
GONGLI YANG $^{1,3}$, QINHUA TAN ${ }^{2}$, YONGMEI XIE ${ }^{2}$, BIN WEI $^{2}$, ZHIXIN CHEN $^{2}$, \\ CHENGWEI TANG ${ }^{2}$, SHENGBAO $\mathrm{LI}^{3}$ and CHUNHUI WANG ${ }^{2}$ \\ ${ }^{1}$ Department of Gastroenterology, Nanfang Hospital, Southern Medical University, Guangzhou, Guangdong 510515; \\ ${ }^{2}$ Department of Gastroenterology, West China Hospital, Sichuan University, Chengdu, Sichuan 610041; \\ ${ }^{3}$ Department of Gastroenterology, Taihe Hospital, Hubei Medical University, Shiyan, Hubei 442000, P.R. China
}

Received June 18, 2013; Accepted October 21, 2013

DOI: $10.3892 /$ etm.2013.1361

\begin{abstract}
Nonsteroidal anti-inflammatory drug-activated gene-1 (NAG-1), a member of the transforming growth factor $\beta$ (TGF- $\beta$ ) superfamily, has been demonstrated to possess antitumorigenic and proapoptotic activities in gastric cancer cells. In the present study, the expression of NAG-1 was assessed in human gastric carcinoma, tumor-adjacent normal tissues and normal gastric mucosa, with the aim to investigate the role of NAG-1 in the carcinogenesis and development of gastric carcinoma. NAG-1 protein expression was evaluated using immunohistochemical staining, while the expression of NAG-1 mRNA was evaluated using reverse transcription-polymerase chain reaction. It was observed that adenocarcinoma tissues had a lower expression of NAG-1 than normal gastric tissues. Furthermore, moderately and well-differentiated adenocarcinoma tissues expressed more NAG-1 protein than the poorly differentiated adenocarcinoma tissues. The expression of NAG-1 protein in adenocarcinoma tissues did not correlate with tumor-node-metastasis staging, infiltration degree or tumor size. The NAG-1 mRNA expression in adenocarcinoma tissues was also lower than that in normal gastric tissues. In conclusion, NAG-1 was poorly expressed in adenocarcinoma tissues and inversely correlated with the degree of tumor differentiation. These results indicate that NAG-1 may have an anti-oncogenic function in the carcinogenesis and development of gastric carcinoma, and that its attenuated or absent expression may lead to gastric carcinogenesis.
\end{abstract}

\section{Introduction}

There is considerable evidence that nonsteroidal anti-inflammatory drugs (NSAIDs) exert antitumor effects through

Correspondence to: Professor Chunhui Wang, Department of Gastroenterology, West China Hospital, Sichuan University, 37 Guoxue Lane, Chengdu, Sichuan 610041, P.R. China

E-mail: sccdwch@163.com

Key words: gastric carcinoma, nonsteroidal anti-inflammatory drug activated gene-1 cyclooxygenase 2 (COX-2)-dependent and independent approaches (1). Furthermore, it has been suggested that nonsteroidal anti-inflammatory drug-activated gene-1 (NAG-1) is capable of inhibiting cell proliferation and promoting apoptosis through various signal transduction pathways. NSAIDs and other chemopreventive phytochemicals are able to induce the expression of NAG-1 in certain tumor cells, and this is considered to be an important non-COX-2 approach by which NSAIDs exert antitumor effects. The role of NAG-1 in gastric cancer carcinogenesis is controversial. We have previously demonstrated that NAG-1 was induced by troglitazone to inhibit the proliferation of a gastric cancer cell line and induce apoptosis in vitro (2). It has been suggested that the overexpression of NAG-1 mRNA in invasive areas in gastric tissues functions as a promoter of tumor progression (3). However, in a different study, NAG-1 protein expression was reported to be low in gastric cancer (4). Thus, in the present study, immunohistochemistry and reverse transcription-polymerase chain reaction (RT-PCR) were employed to assess NAG-1 protein and mRNA expression in gastric cancer and normal tissues, with the aim to investigate the possible role of NAG-1 in the carcinogenesis and development of gastric carcinoma.

\section{Materials and methods}

Research subjects. Forty-six gastric cancer tissue samples were randomly collected from individuals who had undergone gastrectomy for gastric cancer between March 2009 and October 2012 at West China Hospital, Sichuan University (Chengdu, China). The patients included 31 males and 15 females, with a mean age of $56.3 \pm 8.1$ years. In addition, 26 tumor-adjacent normal tissue samples were collected from 17 male and 9 female patients (mean age, 50.3 \pm 9.4 years), and 57 normal gastric mucosa samples were collected by endoscopic biopsy, including 31 males and 26 females (mean age, $57.3 \pm 9.97$ years). All patients provided informed consent for the biopsy procedure. All paraffin sections were generated and examined using hematoxylin and eosin (H\&E) and immunohistochemical staining. Two pathologists independently examined the H\&E-stained sections, employing the World Health Organization Histopathological Grading Standards for gastric cancer. Tumor-adjacent normal tissue samples were 
validated histologically. The fresh tissues were immediately frozen in liquid nitrogen for RNA extraction.

Antibodies and reagents. Anti-NAG-1 rabbit anti-human polyclonal antibody was purchased from Upstate Biotechnology (Lake Placid, NY, USA), while the SP-9001 immunohistochemistry kit and 3,3'-diaminobenzidine (DAB) were obtained from Zhongshan Biotechnology Co., Ltd., (Beijing, China). Triton X-100 was purchased from Sigma (St. Louis, MO, USA) and TRIzol reagent was purchased from Invitrogen Life Technologies (Carlsbad, CA, USA). A Takara RNA PCR kit (Takara, Shiga, Japan) was used in the study.

Immunohistochemistry. Placental tissues were used as positive controls. Paraffin sections were deparaffinized and rehydrated and endogenous peroxidase activity was blocked using $3 \%$ toluene-hydrogen peroxide. The slides were washed with $0.2 \%$ Triton X-100-phosphate-buffered saline (PBS) three times, for $10 \mathrm{~min}$ each, and heat-fixed using a pressure cooker with citrate buffer ( $\mathrm{pH}$ 6.0) for antigen retrieval. A total of $50 \mu \mathrm{l}$ avidin solution (A solution) and $50 \mu \mathrm{l}$ D-biotin solution (B solution) was successively added to each slide to further eliminate endogenous avidin biding activity. The slides were incubated with $50 \mu \mathrm{l}$ rabbit serum for $\sim 20 \mathrm{~min}$ and dried, prior to the addition of $50 \mu 1$ 1:600 NAG-1 polyclonal antibody. Following this, the slides were incubated overnight at $4^{\circ} \mathrm{C}$ and washed with PBS three times, for 5 min each time. A total of $50 \mu 1$ secondary antibody was then added to each slide and incubated at $37^{\circ} \mathrm{C}$ for $20 \mathrm{~min}$. The immunoreaction was developed by incubation with streptavidin horseradish avidin and DAB chromogen. The integrated optical density of each slice was assessed using Image-Pro Plus 5.0 Image Analysis Software (MediaCybernetics, Rockville, MD, USA).

$R T-P C R$ detection. Total RNA was extracted from the fresh tissues using a TRIzol kit, according to the manufacturer's instructions. The RT-PCR was designed in a two-step method. The primer sequences used in the study were as follows: NAG-1 forward, 5'-GCAAGTGACCATGTGCATCGG-3 and reverse, 5'-CAGGAATCGGGTGTCTCAGGAAC-3'; $\beta$-actin forward, 5'-GGGCATGGGTCAGAAGGATT-3' and reverse, 5'-ATGAGGTAGTCAGTCAGGTC-3'. The cDNA synthesis reaction conditions were as follows: $30^{\circ} \mathrm{C}$ for $10 \mathrm{~min}, 42^{\circ} \mathrm{C}$ for $60 \mathrm{~min}, 99^{\circ} \mathrm{C}$ for $5 \mathrm{~min}$ and $5^{\circ} \mathrm{C}$ for $5 \mathrm{~min}$. The PCR system was utilized according to the manufacturer's instructions, with the following reaction conditions: Denaturation for $30 \mathrm{sec}$ at $94^{\circ} \mathrm{C}$, annealing for $30 \mathrm{sec}$ at $60^{\circ} \mathrm{C}$, extension for $45 \mathrm{sec}$ at $72^{\circ} \mathrm{C}, 30$ cycles, extension for $10 \mathrm{~min}$ at $72^{\circ} \mathrm{C}$ and cooling for $10 \mathrm{~min}$ at $4^{\circ} \mathrm{C}$. The final PCR products were loaded onto $1 \%$ agarose gels and images were captured under ultraviolet light. The objective band and $\beta$-actin gray value of the PCR products were measured using Quantity One software ${ }^{\circledR}$ (Bio-Rad, Hercules, CA, USA) and the ratio was taken as an indicator of NAG-1 expression intensity. The PCR products were sent to Shanghai Invitrogen Biotechnology Co, Ltd. (Shanghai, China) for sequencing.

Statistical analysis. SPSS 13.0 statistical software (SPSS, Inc., Chicago, IL, USA) was used for the analysis. One-way analysis of variance was employed for the comparison
Table I. NAG-1 protein expression in tumor-adjacent normal tissues and normal gastric mucosa.

\begin{tabular}{lccc}
\hline Group & Cases & Mean IOD value & P-value \\
\hline $\begin{array}{l}\text { Tumor-adjacent normal } \\
\text { tissues }\end{array}$ & 19 & $80.09 \pm 13.99$ & 0.015 \\
Normal gastric mucosa & 33 & $30.09 \pm 15.45$ & \\
\hline
\end{tabular}

NAG-1, nonsteroidal anti-inflammatory drug activated gene-1; IOD, integreted optical density.

Table II. NAG-1 protein expression in gastric carcinoma tissues and normal gastric mucosa.

\begin{tabular}{lccc}
\hline Group & Cases & $\begin{array}{c}\text { Median IOD value } \\
\text { (Quartile) }\end{array}$ & P-value \\
\hline $\begin{array}{l}\text { Gastric carcinoma } \\
\text { tissues }\end{array}$ & 46 & $2.46(0-26.77)$ & 0.02 \\
$\begin{array}{l}\text { Normal gastric mucosa } \\
\text { Normal }\end{array}$ & 33 & $33.51(15.25-42.58)$ & \\
\hline
\end{tabular}

NAG-1, nonsteroidal anti-inflammatory drug activated gene-1; IOD, integreted optical density.

between the groups showing normal distribution and the Student-Newman-Keuls method was used for pairwise comparisons. The completely randomized rank sum test was employed for comparisons between two groups of non-normal data. The correlation between tumor-node-metastasis (TNM) staging, infiltration degree, tumor size, differentiation and the expression of NAG-1 was analyzed using the Spearman's correlation. $\mathrm{P}<0.05$ was considered to indicate a statistically significant difference.

\section{Results}

Comparison of the NAG-1 protein expression between normal gastric and gastric carcinoma tissues. NAG-1 protein was expressed in the cytoplasm of the placental and normal gastric tissue cells (Fig. 1). Semi-quantitative analysis indicated that the expression of NAG-1 in tumor-adjacent normal gastric tissues was significantly higher than that in the normal gastric mucosa from the endoscopy biopsy ( $\mathrm{P}=0.015$; Table I). NAG-1 protein expression levels were lowest in gastric carcinoma tissues and this expression was significantly lower than that in tumor-adjacent normal tissues $(\mathrm{P}=0.014)$, as well as lower than that in normal gastric mucosa $(\mathrm{P}=0.02$; Table II).

Correlation between NAG-1 expression and degree of tumor differentiation, TNM staging, infiltration degree and tumor size. Semi-quantitative immunohistochemical analysis showed that NAG-1 protein expression in moderately and well-differentiated adenocarcinoma tissues was higher than in poorly differentiated adenocarcinoma tissues $(\mathrm{P}=0.005$; Table III). Spearman's correlation analysis showed that the degree of tumor differentiation and NAG-1 expression intensity were 

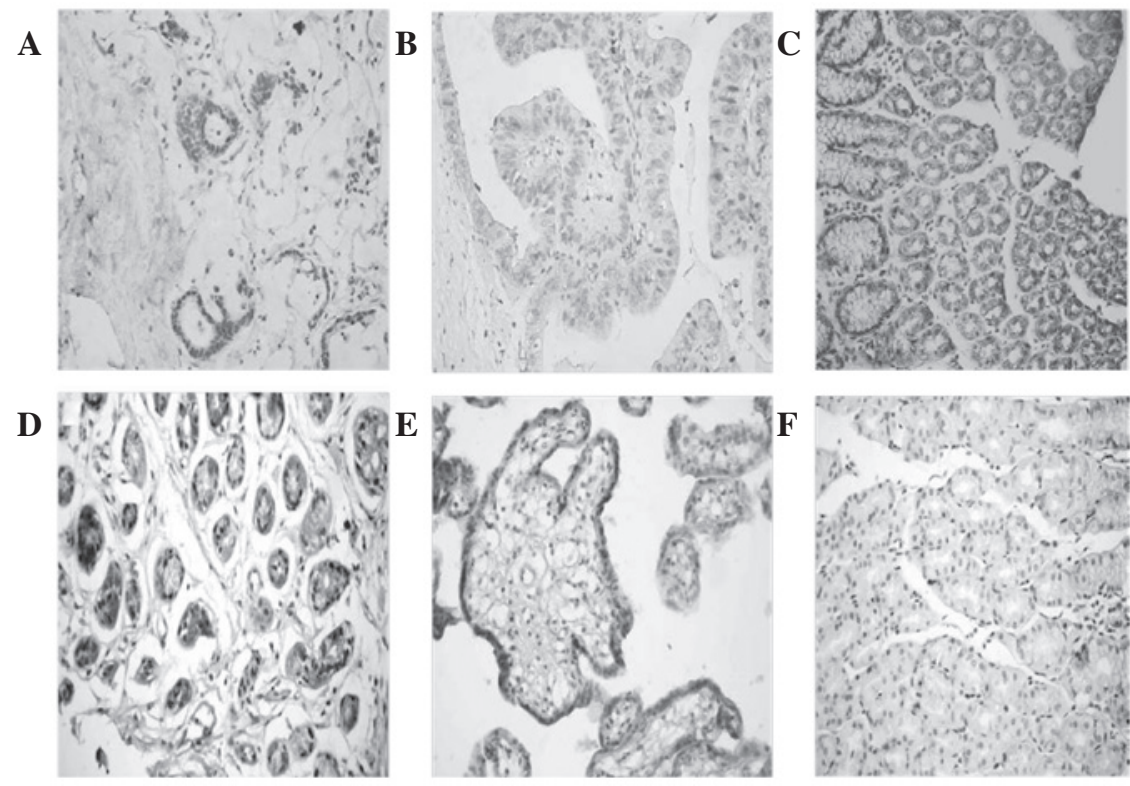

Figure 1. Nonsteroidal anti-inflammatory drug-activated gene-1 protein expression in gastric carcinoma and normal gastric tissues. (A) Poorly differentiated gastric cancer, (B) well-differentiated gastric cancer, (C) tumor-adjacent normal tissues, (D) normal gastric mucosa, (E) placental tissues and (F) normal gastric mucosa (phosphate-buffered saline control) (magnification, $\mathrm{x} 400$ ).

Table III. NAG-1 protein expression in adenocarcinoma tissues.

\begin{tabular}{lccc}
\hline Group & Cases & Mean IOD value & P-value \\
\hline $\begin{array}{l}\text { Poorly differentiated } \\
\text { gastric cancer }\end{array}$ & 28 & $1.33 \pm 1.18$ & 0.005 \\
$\begin{array}{l}\text { Moderately differentiated } \\
\text { and well-differentiated } \\
\text { adenocarcinoma tissues }\end{array}$ & 18 & $13.78 \pm 6.58$ & \\
\hline
\end{tabular}

NAG-1, nonsteroidal anti-inflammatory drug activated gene-1; IOD, integreted optical density.

correlated $(\mathrm{r}=0.854 ; \mathrm{P}=0.03)$. There was no variations in NAG-1 expression intensity in gastric cancer at different TNM stages (stages I-II and III-IV), infiltration degrees (T0-T2 and T3-T4) or tumor sizes (diameter, $\geq 5$ and $<5 \mathrm{~cm}$; Table IV). Spearman's correlation analysis indicated that there was no correlation between NAG-1 expression intensity and the TNM stage, infiltration degree or tumor size of gastric cancer $(r=-0.22,0.007$ and -0.138 , respectively).

Comparison of the expression of NAG-1 $m R N A$ between normal gastric and gastric carcinoma tissues. Gastric carcinoma tissues expressed the lowest levels of NAG-1 mRNA. The expression of NAG-1 mRNA in the tumor-adjacent normal gastric tissues was higher than that in the normal gastric mucosa (Table V and Fig. 2).

\section{Discussion}

NAG-1, a member of the TGF- $\beta$ superfamily, was originally identified in sulindac sulfide-treated HCT-116 colon cancer cells (5). It was later suggested that a variety of NSAIDs were
Table IV. Correlation between NAG-1 protein expression and TNM stage, infiltration degree and tumor size of gastric cancer.

\begin{tabular}{lclc}
\hline Characteristic & Cases & $\begin{array}{c}\text { Median IOD value } \\
\text { (Quartile) }\end{array}$ & P-value \\
\hline $\begin{array}{l}\text { Infiltration degree } \\
\text { T0-T2 }\end{array}$ & 20 & $2.46(0-29.58)$ & 0.96 \\
$\quad$ T3-T4 & 26 & $2.45(1.58-25.52)$ & \\
$\begin{array}{l}\text { TNM staging } \\
\text { Stage I-II }\end{array}$ & 16 & $3.87(0-32.36)$ & 0.139 \\
$\quad$ Stage III-IV & 30 & $2.95(1.43-23.18)$ & \\
$\begin{array}{l}\text { Tumor size, cm } \\
\geq 5\end{array}$ & & & \\
$<5$ & 24 & $2.76(0-17.99)$ & 0.089 \\
& 22 & $3.17(0-31.02)$ & \\
\hline
\end{tabular}

NAG-1, nonsteroidal anti-inflammatory drug activated gene-1; TNM, tumor node metastasis; IOD, integreted optical density.

able to induce NAG-1 gene expression to exert antitumor effects, independent of COX-2. Therefore, this was considered to be one of the most important non-COX-2 approaches by which NSAIDs elicited antitumor effects. In addition to NSAIDs, a number of phytochemicals, including resveratrol (6), genistein (7), diallyl disulfide (8), indole-3-methanol (9), retinoic acid (10) and PPAR $\gamma$ ligands (11), have been shown to be capable of promoting apoptosis and mediating antitumor effects by inducing the expression of NAG-1. NAG-1, also known as placental transforming growth factor $\beta$ (12), macrophage inhibitory cytokine 1 (13), placental bone morphogenetic protein (14), prostate differentiation factor (15) and growth differentiation factor 15 (16), is highly expressed in the human placenta and prostate and weakly expressed in the kidney and pancreas (15). The NAG-1 prodomain consists 
Table V. NAG-1 mRNA expression in normal gastric and gastric carcinoma tissues.

\begin{tabular}{lccc}
\hline Group & Cases & Mean gray scale & P-value \\
\hline $\begin{array}{l}\text { Gastric carcinoma } \\
\text { tissues }\end{array}$ & 19 & $0.8210 \pm 0.10173$ & \\
$\begin{array}{l}\text { Tumor-adjacent } \\
\text { normal tissues }\end{array}$ & 26 & $1.8246 \pm 0.14971$ & $0.012^{\mathrm{a}}$ \\
$\begin{array}{l}\text { Normal gastric mucosa } \\
\text { 24 }\end{array}$ & 24 & $1.1675 \pm 0.08779$ & $0.027^{\mathrm{a}}$; \\
\hline
\end{tabular}

${ }^{\mathrm{a}}$ vs. gastric carcinoma tissues; ${ }^{\mathrm{b}} \mathrm{vs}$. tumor-adjacent normal tissues. NAG-1, nonsteroidal anti-inflammatory drug activated gene-1 .

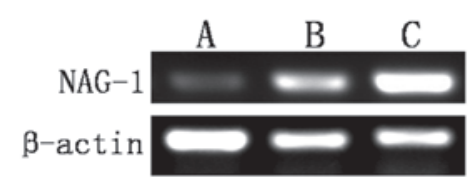

Figure 2. NAG-1 mRNA expression in normal gastric and gastric carcinoma tissues. A, gastric cancer tissues; B, normal gastric mucosa; C, tumor-adjacent normal tissues. NAG-1, nonsteroidal anti-inflammatory drug-activated gene-1.

of 167 amino acids and contains an $N$-linked glycosylation site (17). Following dimerization of the full-length pro-NAG-1 precursor by a disulfide linkage, the dimeric pro-protein undergoes proteolytic cleavage catalyzed by furin-like protease at the sequence RXXR, resulting in the release of a 112-amino acid C-terminal dimeric mature region. The mature dimer is then secreted into the extracellular media. Therefore, NAG-1 may have multiple forms in the cell, including the pro-NAG-1 monomer, the pro-NAG-1 dimer, the pro-peptide N-terminal fragment following cleavage and the mature dimer.

The role of NAG-1 in the development and progression of cancer is complex and poorly understood. In vitro and in vivo studies in colon and prostate cancer and some experimental evidence have suggested that NAG-1 exhibits tumor-suppressor activity (18-21), while other data have suggested that it has oncogenic activity $(22,23)$. Similarly, the role of NAG-1 in gastric cancer carcinogenesis is also controversial. NAG-1 has been demonstrated to stimulate the growth of a number of gastric cell lines, mediated by the activation of the extracellular signal-regulated kinase $1 / 2$ (ERK1/2) pathway (3). In addition, NAG-1 has been shown to activate the protein kinase $B$ and ERK1/2 pathways in human breast and gastric cells by the transactivation of the ErbB2/human epidermal growth factor receptor 2 oncogene (24). A clinical study revealed that NAG-1 expression was upregulated in the serum of patients with gastric cancer and that its expression markedly correlated with cancer metastasis, suggesting an oncogenic role for NAG-1 during gastric cancer progression (25). By contrast, the NAG-1 gene is capable of being induced by NSAIDs $(26,27)$ and troglitazone (2) to inhibit the proliferation of the gastric cancer cell line and induce apoptosis in vitro, suggesting that NAG-1 functions as a tumor suppressor in the development of gastric cancer.
In the present study, it was observed that NAG-1 protein expression levels were lowest in gastric carcinoma tissues, and that this expression was significantly lower than that of tumor-adjacent normal tissues, as well as normal gastric mucosa. This suggested that NAG-1 may function as a tumor-suppressor gene in gastric cancer carcinogenesis. The expression of NAG-1 protein in human gastric carcinoma was further analyzed to evaluate its correlation with specific clinical features. NAG-1 protein expression exhibited no correlation with tumor infiltration degree, TNM stage or tumor size, which was inconsistent with the study by Park et al (4). The NAG-1 protein expression intensity was inversely correlated with the differentiation of gastric cancer, suggesting that NAG-1 may be involved in regulating the differentiation of gastric cancer. Furthermore, the NAG-1 protein expression in tumor-adjacent normal gastric tissues was higher than that in the normal gastric mucosa, which was attributed to the relatively superficial sampling of the endoscopic biopsy.

NAG-1 expression in normal and cancer tissues has been investigated in a number of studies, which were subsequently reviewed by Mimeault and Batra (28). Collectively, there is no clear consensus regarding the expression levels of NAG-1 in tumors compared with normal tissues, although the majority of the data indicate higher expression in tumors relative to normal tissues. One consideration is the variations in methodologies used to measure NAG-1 expression by different investigators (29). The specificity of the antibodies used to measure the expression of NAG-1 in a number of the studies is frequently not clearly stated. The use of an antibody that detects the monomer form, while poorly reacting with the dimer form, is likely to yield conflicting expression data when compared with the use of an antibody that reacts well with the dimer and poorly with the monomers.

Notably, it was observed in the present study that NAG-1 protein was exclusively expressed in the cytoplasm of gastric glands in the normal gastric mucosa, which was inconsistent with the results of the study by Kim et al (30), in which NAG-1 was exclusively expressed in the colonic epithelial membrane lining. This demonstrates that there are secretory NAG-1 protein forms and variations in the activity of the cleaving enzyme which cleave pro-NAG-1 from the RXXR site in different tissues. The activity of the cleaving enzyme is capable of influencing the level of NAG-1 inside the cell, as the cleaved NAG-1 is rapidly secreted. However, the majority of the studies did not examine the activity of the cleaving enzyme when analyzing NAG-1 expression. Thus, NAG-1 expression studies, which are conducted by the measurement of protein expression, must be assessed with caution. Previously, Kadowaki et al (31) performed an ELISA in a glioma cell line and normal and glioblastoma tumor samples, revealing that the correlation between the gene copy number and the expression of the pro-NAG-1 in the cells and the concentration of secreted NAG-1, were inconsistent. In specific cells, the majority of NAG-1 was in the secreted form in the media, while in other cells, NAG-1 remained as the pro-NAG-1 inside the cells. Thus, the measurement of gene copy number is a better estimate of NAG-1. Therefore, in the present study, RT-PCR was performed to assess the expression of NAG-1 mRNA in gastric cancer and normal gastric tissues. In addition, PCR products were confirmed by sequencing. The results showed that the 
expression of NAG-1 mRNA was low in gastric cancer, significantly lower than that of the tumor-adjacent normal tissues and normal gastric mucosa. This was consistent with the immunohistochemical results, which further demonstrated that the absence of NAG-1 is involved in gastric tumorigenesis.

In conclusion, the present study demonstrated that NAG-1 protein and mRNA levels in gastric carcinoma are significantly lower than those in the tumor-adjacent normal tissues and normal gastric mucosa, suggesting that NAG-1 may have a negative regulatory role in gastric cancer by acting as a tumor-suppressor gene. This indicates that low NAG-1 expression may lead to cancer. In-depth studies of NAG-1 are likely to enhance the understanding of the antitumor effect of NSAIDs and also provide a novel target for the prevention and treatment of gastric cancer.

\section{Acknowledgements}

This study was supported by the Research Program of Sichuan Provincial Department of Science and Technology (no. 04SG022-015-05).

\section{References}

1. Wang R, Guo L, Wang P, et al: Chemoprevention of cancers in gastrointestinal tract with cyclooxygenase 2 inhibitors. Curr Pharm Des 19: 115-125, 2012.

2. Wang $\mathrm{C}$, Wang $\mathrm{J}$ and Bai P: Troglitazone induces apoptosis in gastric cancer cells through the NAG-1 pathway. Mol Med Rep 4: 93-97, 2011.

3. Lee DH, Yang Y, Lee SJ, et al: Macrophage inhibitory cytokine-1 induces the invasiveness of gastric cancer cells by up-regulating the urokinase-type plasminogen activator system. Cancer Res 63 : 4648-4655, 2003.

4. Park JY, Park KH, Bang S, Kim MH, Koh SS and Song SY: Expression of nonsteroidal anti-inflammatory drug-activated gene-1 (NAG-1) inversely correlates with tumor progression in gastric adenomas and carcinomas. J Cancer Res Clin Oncol 134: 1029-1035, 2008.

5. Baek SJ, Kim KS, Nixon JB, Wilson LC and Eling TE: Cyclooxygenase inhibitors regulate the expression of a TGF-beta superfamily member that has proapoptotic and antitumorigenic activities. Mol Pharmacol 59: 901-908, 2001.

6. Baek SJ, Wilson LC and Eling TE: Resveratrol enhances the expression of non-steroidal anti-inflammatory drug-activated gene (NAG-1) by increasing the expression of p53. Carcinogenesis 23: 425-434, 2002 .

7. Wilson LC, Baek SJ, Call A and Eling TE: Nonsteroida anti-inflammatory drug-activated gene (NAG-1) is induced by genistein through the expression of p53 in colorectal cancer cells. Int J Cancer 105: 747-753, 2003.

8. Bottone FG Jr, Baek SJ, Nixon JB and Eling TE: Diallyl disulfide (DADS) induces the antitumorigenic NSAID-activated gene (NAG-1) by a p53-dependent mechanism in human colorectal HCT 116 cells. J Nutr 132: 773-778, 2002.

9. Lee SH, Kim JS, Yamaguchi K, Eling TE and Baek SJ: Indole-3-carbinol and 3,3'-diindolylmethane induce expression of NAG-1 in a p53-independent manner. Biochem Biophys Res Commun 328: 63-69, 2005.

10. Newman D, Sakaue M, Koo JS, et al: Differential regulation of nonsteroidal anti-inflammatory drug-activated gene in normal human tracheobronchial epithelial and lung carcinoma cells by retinoids. Mol Pharmacol 63: 557-564, 2003.

11. Baek SJ, Kim JS, Nixon JB, DiAugustine RP and Eling TE: Expression of NAG-1, a transforming growth factor-beta superfamily member, by troglitazone requires the early growth response gene EGR-1. J Biol Chem 279: 6883-6892, 2004.
12. Li PX, Wong J, Ayed A, et al: Placental transforming growth factor-beta is a downstream mediator of the growth arrest and apoptotic response of tumor cells to DNA damage and p53 overexpression. J Biol Chem 275: 20127-20135, 2000.

13. Bootcov MR, Bauskin AR, Valenzuela SM, et al: MIC-1, a novel macrophage inhibitory cytokine, is a divergent member of the TGF-beta superfamily. Proc Natl Acad Sci USA 94: 11514-11519, 1997.

14. Hromas R, Hufford M, Sutton J, Xu D, Li Y and Lu L: PLAB, a novel placental bone morphogenetic protein. Biochim Biophys Acta 1354: 40-44, 1997.

15. Paralkar VM, Vail AL, Grasser WA, et al: Cloning and characterization of a novel member of the transforming growth factor-beta/bone morphogenetic protein family. J Biol Chem 273: 13760-13767, 1998.

16. Böttner M, Laaff M, Schechinger B, Rappold G, Unsicker K and Suter-Crazzolara C: Characterization of the rat, mouse, and human genes of growth/differentiation factor-15/macrophage inhibiting cytokine-1 (GDF-15/MIC-1). Gene 237: 105-111, 1999.

17. Bauskin AR, Zhang HP, Fairlie WD, et al: The propeptide of macrophage inhibitory cytokine (MIC-1), a TGF-beta superfamily member, acts as a quality control determinant for correctly folded MIC-1. EMBO J 19: 2212-2220, 2000.

18. Tan M, Wang Y, Guan K and Sun Y: PTGF-beta, a type beta transforming growth factor (TGF-beta) superfamily member, is a p53 target gene that inhibits tumor cell growth via TGF-beta signaling pathway. Proc Natl Acad Sci USA 97: 109-114, 2000.

19. Liu T, Bauskin AR, Zaunders J, et al: Macrophage inhibitory cytokine 1 reduces cell adhesion and induces apoptosis in prostate cancer cells. Cancer Res 63: 5034-5040, 2003.

20. Lambert JR, Kelly JA, Shim M, et al: Prostate derived factor in human prostate cancer cells: gene induction by vitamin $\mathrm{D}$ via a p53-dependent mechanism and inhibition of prostate cancer cell growth. J Cell Physiol 208: 566-574, 2006.

21. Baek SJ, Okazaki R, Lee SH, et al: Nonsteroidal anti-inflammatory drug-activated gene-1 over expression in transgenic mice suppresses intestinal neoplasia. Gastroenterology 131: 1553-1560, 2006

22. Brown DA, Ward RL, Buckhaults P, et al: MIC-1 serum level and genotype: associations with progress and prognosis of colorectal carcinoma. Clin Cancer Res 9: 2642-2650, 2003.

23. Senapati S, Rachagani S, Chaudhary K, Johansson SL, Singh RK and Batra SK: Overexpression of macrophage inhibitory cytokine-1 induces metastasis of human prostate cancer cells through the FAK-RhoA signaling pathway. Oncogene 29: 1293-1302, 2010

24. Kim KK, Lee JJ, Yang Y, You KH and Lee JH: Macrophage inhibitory cytokine-1 activates AKT and ERK-1/2 via the transactivation of ErbB2 in human breast and gastric cancer cells. Carcinogenesis 29: 704-712, 2008.

25. Baek KE, Yoon SR, Kim JT, et al: Upregulation and secretion of macrophage inhibitory cytokine-1 (MIC-1) in gastric cancers. Clin Chim Acta 401: 128-133, 2009.

26. Pang RP, Zhou JG, Zeng ZR, et al: Celecoxib induces apoptosis in COX-2 deficient human gastric cancer cells through Akt/GSK3beta/NAG-1 pathway. Cancer Lett 251: 268-277, 2007.

27. Jang TJ, Kang HJ, Kim JR and Yang CH: Non-steroidal anti-inflammatory drug activated gene (NAG-1) expression is closely related to death receptor- 4 and -5 induction, which may explain sulindac sulfide induced gastric cancer cell apoptosis. Carcinogenesis 25: 1853-1858, 2004.

28. Mimeault M and Batra SK: Divergent molecular mechanisms underlying the pleiotropic functions of macrophage inhibitory cytokine-1 in cancer. J Cell Physiol 224: 626-635, 2010.

29. Wang X, Baek SJ and Eling TE: The diverse roles of nonsteroidal anti-inflammatory drug activated gene (NAG-1/GDF15) in cancer. Biochem Pharmacol 85: 597-606, 2013.

30. Kim KS, Baek SJ, Flake GP, Loftin CD, Calvo BF and Eling TE: Expression and regulation of nonsteroidal anti-inflammatory drug-activated gene (NAG-1) in human and mouse tissue. Gastroenterology 122: 1388-1398, 2002.

31. Kadowaki M, Yoshioka H, Kamitani H, Watanabe T, Wade PA and Eling TE: DNA methylation-mediated silencing of nonsteroidal anti-inflammatory drug-activated gene (NAG-1/GDF15) in glioma cell lines. Int J Cancer 130: 267-277, 2012. 